\title{
Federal Policy for Lowering Prescription Drug Prices
}

\section{Amanda Hurley ${ }^{1}$, Celeste M. Sheftel ${ }^{2}$, Alejandra Canales $^{3}$}

\author{
1University of Wisconsin-Madison, Department of Plant Pathology, Wisconsin Institute for \\ Discovery, Madison, WI \\ ${ }^{2}$ University of Wisconsin-Madison, Molecular and Cellular Pharmacology Training Program, \\ Madison, WI \\ ${ }^{3}$ University of Wisconsin Madison, Neuroscience Training Program, Madison, WI \\ http://doi.org/10.38126/ISPG170110 \\ Corresponding author: ahurley2@wisc.edu
}

Keywords: drug pricing; prescriptions; law; healthcare; patents; drug patent exemption

Executive Summary: Both Republicans and Democrats are determined to lower the escalating cost of prescription drug prices, which is projected to reach $\$ 605$ billion/yr by 2026 (Committee on Ways and Means 2019). In this memorandum, we explore the possible outcomes of,

1) linking U.S. drug prices to the international median incentivized by reimportation of the U.S.-made drugs from other countries,

2) allowing the Secretary of Health and Human Services (HHS) to negotiate Medicare part D drugs incentivized through patent exemption and,

3) funding drug discovery through prizes instead of market-exclusive patents.

We recommend that the next presidential candidate approve Option 2 and advocate for HHS Secretary negotiation powers with patent exemptions for non-compliant companies.

\section{Statement of issue}

In the United States, pharmaceutical drug prices are escalating, resulting in "medication insecurity" - the inability to pay for prescription medicine. Medication insecurity affects approximately $22 \%$ of seniors and more than $30 \%$ of adults skip or decrease doses of their medications in response to inflated prices (Safran et al. 2002; Cohen et al. 2019). Rationing important prescriptions, such as insulin, can result in death (Right Care Alliance 2019). Out of all industrialized countries, the U.S. has the highest rates of insulin rationing (T1international 2018). The total spending per person on insulin doubled between 2012 and 2016, despite the unchanging demand (Biniek and Johnson 2019). Due to this surge in price, "insulin caravans" have become popularized where people can purchase insulin over the counter in
Canada for $\$ 30$ compared to $\$ 300$ (without insurance) in the U.S. (Dossey 2019). Currently, the insulin market in the U.S. is limited to three companies: Eli Lilly, Novo Nordisk, and Sanofi, thus creating a near-monopoly (Cefalu et al. 2018).

\section{Challenges}

Many manufacturers link the high cost of prescription drugs to the research and development of failed drugs (Emanuel 2019). Profit margins of the top twenty-five pharmaceutical companies, however, are double or even triple the margins of other industries, demonstrating ample room for financial compromise (U.S. Government Accountability Office 2017, 17-19). Competition does not drive prices down because companies hold mini-monopolies with patents protecting new drugs to preserve innovation 
incentives. To be successful, new policies must address skyrocketing prescription drug prices while preserving innovation in American drug production.

The COVID-19 pandemic and subsequent concern over the inaccessibility of testing and treatment has added more urgency to the need for aggressive action to curb the pharmaceutical industry's profiteering motives. Also, the economic recession in the wake of an inadequate national pandemic response has further exacerbated these worries as American health insurance is tied to employment. Lawmakers insisted that HHS should provide a limited license rather than a market-exclusive patent to any private manufacturer to ensure the affordability of any new vaccine or treatment (Congresswoman Jan Schakowsky 2020). Although the Coronavirus Preparedness and Response Supplemental Appropriations Act signed into law on March 6, 2020, does not include any such language, the legislation includes a provision authorizing the HHS Secretary to set reasonable prices for any vaccines or treatments purchased by the government (Simmons-Duffin 2020). Secretary Azar has notably refused to make any promises that he would use that authority (Azar 2020).

\section{Government stance}

The federal government began covering outpatient prescription drugs for Medicare recipients in 2006 under Section D of the Medicare Modernization Act (MMA) (Lichtenberg and Sun 2007), which as of 2019 accounts for $21 \%$ of the market (Mikuli 2019). Notably, two policies under MMA directly benefit pharmaceutical companies:

1) Drugs cannot be imported from other countries and,

2) HHS is strictly prohibited from negotiating drug prices.

Several recent legislative efforts have focused on ways to lower drug prices. The Elijah E. Cummings Lower Drug Costs Now Act sponsored by Congressman Frank Pallone Jr. (D-NJ) (Pallone 2019) would allow the Centers for Medicare \& Medicaid Services (CMS) to negotiate prices for insulin products and 25 of the top-selling brand-name drugs on behalf of Medicare and Medicare Advantage recipients. Prices were not to exceed more than $120 \%$ of the median price in six developed countries, and civil and tax penalties would be levied against drug manufacturers failing to comply with these new regulations. The lowered rates would also be offered to private insurers unless they chose to opt-out. The nonpartisan Congressional Budget Office estimates that this bill would reduce federal spending by $\$ 345$ billion from 2020-2029 (Swagel 2019).

Similarly, the Senate has also recognized the need to lower drug prices. Senator Chuck Grassley (R-IA) introduced Senate Bill S. 2543, the Prescription Drug Pricing Reduction Act of 2019 (Grassley 2019), which requires drug manufacturers to issue rebates for drugs whose cost exceeds the inflation rate. To increase transparency, this bill would also require the CMS to publish information relating to drug rebates and discounts as well as payments between pharmacy benefit managers, health plans, and pharmacies. Senate Majority Leader Mitch McConnell (R-KY) has not signaled any inclination to move either the House or Senate bill up for a vote.

\section{Policy options}

\section{i. Implement the median international price}

incentivized by the re-importation of U.S.-made drugs

As mentioned above, H.R.3 SEC 1191 proposes linking the U.S. drug prices to the median pharmaceutical prices in the following countries: United Kingdom, Canada, Germany, France, Japan, and Australia (Pallone 2019). We propose amending the current bill by requiring pharmaceutical prices not exceed $120 \%$ of the median pharmaceutical price of the aforementioned countries, as U.S. drug prices are currently, on average, $400 \%$ of the international median price. If pharmaceutical companies fail to comply, HHS can re-import U.S.-made drugs from countries and sell the pharmaceuticals at a government-set price, i.e. the international median.

\section{Advantages}

- Direct reduction of pharmaceutical drug prices

- Medicare part D would save $\$ 49$ billion alone (Committee on Ways and Means 2019)

- Increase U.S. revenue on pharmaceuticals

- 1.8 million Americans spend \$1 billion annually importing cheaper pharmaceuticals from Canada (Johnson 2005) 
- Re-importing drugs and/or selling at $120 \%$ of the international median price would stimulate the U.S. economy

\section{Disadvantages}

- Government price regulation may increase shortages in the long run (Segal 2010)

- Shortages lead to black market sales and rationing

- This is presently a burden for Americans, particularly insulin users

- Re-importation of U.S.-made pharmaceuticals may lead to shortages abroad

- Canada is unsupportive of U.S. reimportation due to the potential shortages (Bhosle and Balkrishnan 2007)

- The integrity of the drug may become compromised

- The Food and Drug Administration (FDA) cannot regulate the storage and/or packaging in other countries

- The FDA is concerned about the importation of counterfeit drugs (Meadows 2002)

ii. Incentivize HHS Secretary negotiations of Medicare Part D drugs through patent exemption.

As in H.R.3 SEC. 1194, the HHS Secretary will regain the ability to negotiate prices, especially for drugs that would impart the greatest cost savings onto the federal government or Medicare payers. Importantly, only 20 drugs constituted $20 \%$ of a $\$ 463$ billion market in 2018 (Blankenship 2019). Rather than implement legislative price caps, negotiations will be unrestricted. Pharmaceutical companies will be incentivized to negotiate with the HHS Secretary because the penalty for non-compliance will be the removal of compound-specific market exclusivity through patent exemption.

A patent exemption would thus allow for the production of generics by competing companies, lowering drug prices. To accomplish this, legislative amendments will target two bills: the noninterference section of the MMA bill SEC. 1860D11 shall be repealed to give the HHS secretary bargaining power, and the FDA Safe Harbor exemption within the Hatch-Waxman Act shall be expanded to include Medicare non-compliant companies (Russo and Johnson 2015).

\section{Advantages}

- Bipartisan legislative amendments

- No target prices or international scales; cannot be branded as "price control"

- The penalty is not a tax; stabilizes market through competition

- Discourages price hikes

○ Tax penalty, instead of a patent exemption, could lead companies to try to recuperate the lost revenue

- Directly attacks the dual problems of monopolies: price- and production-control

- FDA is interested in collaborating on genericfriendly policies (Office of the Commissioner 2018)

\section{Disadvantages}

- Current stagnation in drug pricing legislation

- Requires policy changes in collaboration with the FDA for best results (Fox 2017)

- Revamp Risk Evaluation and Mitigation Strategies

- Disallow corporations to apply for "citizen petitions" to extend patents

- Remove "authorized generics," which are usually just re-branded drugs from the same company

iii. Fund drug discovery through prizes instead of market-exclusive patents

As in Senate Bill S.495 (Sanders 2017), the Medical Prize Innovation Act, the U.S. government would set aside $0.55 \%$ of the national GDP to establish a fund that would award prize payments for the development of new drugs and biological products, as defined in 21 USC. Sec 3212012 and 42 USC. Sec 262 2011 , respectively. The award would be in place of a market-exclusive patent, and a board of trustees with leadership from the CMS, FDA, National Institutes of Health, and Centers for Disease Control would award the prize. This board would also establish the selection criteria for prize recipients and independent advisory expert committees that would provide insight into the drug development process from both economic and scientific perspectives. The money for this fund could come from fees on health insurers, as in the original text for S.495, or from taxes on pharmaceutical companies.

Advantages 
- Eliminate exclusive rights to manufacture, distribute, or sell any new drug or biological product

- Price would no longer be subject to profit motives of pharmaceutical companies

- Introduce true competition into drug manufacturing

- Preserve incentives for innovation

- Prize amount could be scaled depending on the severity of the condition being treated

- Funds could reward open and collaborative research practices

- Pharmaceutical companies may continue to produce drugs based on market demand

\section{Disadvantages}

- May face steep opposition from pharmaceutical companies

- Likely a decrease in their profit margins

- Needs to be taken together with other actions aimed at reducing the cost of existing medications

- Would most readily apply to medications that have not yet been developed

\section{Recommendations}

We recommend that the next presidential candidate approve Option 2 and advocate for the repeal of the noninterference section from the MMA. Giving the HHS Secretary the power to negotiate Medicare Part D drug prices would provide the government with an immediate way to lower the prices of prescription drugs and provide relief to the public. Expanding patent exemption under the FDA Safe Harbor to include non-compliant companies gives leverage to HHS negotiations and potentially provides avenues to break down mini-monopolies by introducing competition.

We also recommend that the candidate works towards establishing a medical prize innovation fund as a long-term investment to improve how America funds drug discovery.

\section{Appendix}

The production of lifesaving drugs by overbearing pharmaceutical companies is not unique to the insulin market. Hepatitis C antiviral therapies, for example, are classified as an "essential medication" by the World Health Organization (Chapman and Buckley 2017). In the U.S., approximately 1.2 to 4.7 million people-predominantly low-income-are diagnosed with Hepatitis C, making it one of the most common blood-borne infections. However, the price of a 12-week treatment regimen ranges from $\$ 54,000$ to $\$ 94,500$ per person before insurance or rebates (National Academies of Sciences, Engineering, and Medicine et al. 2016, 111; Chapman and Buckley 2017). This high price of life-saving drugs coupled with a large demand for treatment has pushed both public and private insurers to impose restrictions excluding people from obtaining the treatment they require. Diabetes and Hepatitis $\mathrm{C}$ are only two examples of lethal diseases for which we have pharmaceutical treatments that are inaccessible to Americans due to price.

\section{References}

Azar, Alex. 2020. "Federal Health Officials Testify on Coronavirus and 2021 Budget Request." CSPAN.org. February 26, 2020. https://www.cspan.org/video/?469562-1/federal-healthofficials-testify-coronavirus-2021-budget$\underline{\text { request\&start }=10861}$

Bhosle, Monali J., and Rajesh Balkrishnan. 2007. "Drug Reimportation Practices in the United States." Therapeutics and Clinical Risk Management 3 (1): 41-46.
Biniek, Jean Fuglesten, and William Johnson. 2019. "Spending on Individuals with Type 1 Diabetes and the Role of Rapidly Increasing Insulin Prices." Health Care Cost Institute.

Blankenship, Kyle. 2019. "The Top 20 Drugs by 2018 U.S. Sales." FiercePharma. Accessed April 4, 2020. https://www.fiercepharma.com/specialreport/top-20-drugs-by-2018-u-s-sales. 
Cefalu, William, T., Dawes, Daniel E., Gavlak, Gina, Goldman, Dana, Herman, William H., van Nuys, Karen, Powers, Alvin C., Taylor, Simeon I., and Alan L. Yatvin. 2018. "Insulin Access and Affordability Working Group: Conclusions and Recommendations." Diabetes Care. 41(6):12991311. http://dx.doi.org/10.2337/dci18-0019

Chapman, Audrey R., and Thomas Buckley. 2017. "Lowering the High Cost of Hepatitis C Drugs." Journal of Pharmaceutical Care \& Health Systems. https://doi.org/10.4172/2376-0419.1000187.

Cohen, Robin A., Peter Boersma, and Anjel Vahratian. 2019. "Strategies Used by Adults Aged 18-64 to Reduce Their Prescription Drug Costs, 2017." NCHS Data Brief, no. 333 (March): 1-8.

Committee on Ways and Means. 2019. "A Painful Pill to Swallow: U.S. vs. International Prescription Drug Prices." Accessed April 9, 2020. https://waysandmeans.house.gov/sites/democra ts.waysandmeans.house.gov/files/documents/U. S.\%20vs.\%20International\%20Prescription $\% 20$ Drug\%20Prices_0.pdf.

Congresswoman Jan Schakowsky. 2020. "House Democrats Demand Fair Drug Pricing For Taxpayer-Funded Coronavirus Vaccine or Treatment." February 20, 2020. https://schakowsky.house.gov/media/pressreleases/house-democrats-demand-fair-drugpricing-taxpayer-funded-coronavirus-vaccine-or.

Dossey, Larry. 2019. "The Insulin Caravans: What Price Life?" Explore. November. https://doi.org/10.1016/i.explore.2019.11.001.

Emanuel, Ezekiel J. 2019. "Big Pharma's Go-To Defense of Soaring Drug Prices Doesn't Add Up." The Atlantic. March 23, 2019. https://www.theatlantic.com/health/archive/20 19/03/drug-prices-high-cost-research-anddevelopment/585253/.

Fox, Erin. 2017. "How Pharma Companies Game the System to Keep Drugs Expensive." Harvard Business Review. April 6, 2017. https://hbr.org/2017/04/how-pharmacompanies-game-the-system-to-keep-drugsexpensive.

Grassley, Chuck. 2019. "S.2543 - 116th Congress (20192020): Prescription Drug Pricing Reduction Act of 2019," September. https://www.congress.gov/bill/116thcongress/senate-bill/2543.

Johnson, Nicole. 2005. "Canadian Drug Reimportation Debate Goes on." Drug Discovery Today. 10 (10):678-9 https://doi.org/10.1016/s13596446(05)03456-2.
Lichtenberg, Frank R. and Shawn X. Sun. 2007. The Impact Of Medicare Part D On Prescription Drug Use By The Elderly. Health Affairs._Accessed April 4, 2020a.

https://www.healthaffairs.org/doi/full/10.1377 hhlthaff.26.6.1735.

Meadows, Michelle. 2002. "Imported Drugs Raise Safety Concerns." FDA Consumer 36 (5): 18-23.

Mikuli, Matej. 2019 "Health Care Expenditure Distribution by Payer U.S. 2019." Statista. Accessed April 4, 2020.

https://www.statista.com/statistics/237043/ushealth-care-spending-distribution/.

National Academies of Sciences, Engineering, and Medicine, Health and Medicine Division, Board on Population Health and Public Health Practice, and Committee on a National Strategy for the Elimination of Hepatitis B and C. 2016. Eliminating the Public Health Problem of Hepatitis B and $C$ in the United States: Phase One Report. National Academies Press.

Office of the Commissioner. 2018. "Statement from FDA Commissioner Scott Gottlieb, M.D., on New Policies to Reduce the Ability of Brand Drug Makers to Use REMS Programs as a Way to Block Timely Generic Drug Entry, Helping Promote Competition, and Access." U.S. Food and Drug Administration. https://www.fda.gov/newsevents/press-announcements/statement-fdacommissioner-scott-gottlieb-md-new-policiesreduce-ability-brand-drug-makers-use-rems.

Pallone, Frank Jr. 2019. "H.R.3 - 116th Congress (20192020): Elijah E. Cummings Lower Drug Costs Now Act," December. https://www.congress.gov/bill/116thcongress/house-bill/3.

Right Care Alliance. 2019 "High Insulin Costs Are Killing Americans - Right Care Alliance."Accessed April 4, 2020.

https://rightcarealliance.org/actions/insulin/.

Russo, Alice. A., and Jason Johnson. 2015. "Research Use Exemptions to Patent Infringement for Drug Discovery and Development in the United States." Cold Spring Harbor Perspectives in Medicine. https://doi.org/10.1101/cshperspect.a020933.

Safran, Dana Gelb, Neuman, Patricia, Schoen, Cathy, Montgomery, Jana E. Li, Wenjun, Wilson, Ira B., Kitchman, Michelle S., Bowen, Andrea E., and William H. Rogers. 2002. "Prescription Drug Coverage and Seniors: How Well Are States Closing the Gap?" Health Affairs Suppl Web Exclusives (July): W253-68. 
Sanders, Bernard 2017. "S.495 - 115th Congress (20172018): Medical Innovation Prize Fund Act," https://www.congress.gov/bill/115thcongress/senate-bill/495/

Segal, Troy. 2010. "Price Ceiling." Investopedia. August 8, 2010.

https://www.investopedia.com/terms/p/priceceiling.asp.

Simmons-Duffin, Selena. 2020. "Where That \$8.3 Billion In U.S. Coronavirus Funding Will And Won't Go." NPR.org. March 6, 2020. https://www.npr.org/sections/healthshots/2020/03/06/812964894/where-that-8-3billion-in-u-s-coronavirus-funding-will-andwont-go.

Swagel, Philip L. 2019. "Effects of Drug Price Negotiation Stemming From Title 1 of H.R. 3, the Lower Drug Costs Now Act of 2019, on Spending and Revenues Related to Part D of Medicare." Congressional Budget Office. Accessed April 4, 2020b. https://www.cbo.gov/system/files/201910/hr3ltr.pdf.
T1interational. 2018 "Costs and Rationing of Insulin and Diabetes Supplies: Findings from the T1international Patient Survey." Accessed July 16, 2020.

https://www.t1international.com/media/assets/ file/T1International Report -

Costs and Rationing of Insulin Diabetes Suppli es 2.pdf

21 USC. Sec 321. 2012. "Definitions; Generally." Accessed April 4, 2020. https://uscode.house.gov/view.xhtml?req=(title: 21\%20section:321\%20edition:prelim

42 USC. Sec 262. 2011. "Regulation of Biological Products." Accessed April 4, 2020. https://uscode.house.gov/view.xhtml?req=(title: 42\%20section:262\%20edition:prelim

U.S. Government Accountability Office. 2017. "Drug Industry: Profits, Research and Development Spending, and Merger and Acquisition Deals," no. GAO-18-40

(December). https://www.gao.gov//assets/690/688472.pdf/

Amanda Hurley received a Ph.D. in Molecular Biology with Dr. Bonnie Bassler at Princeton University in 2017. She serves as the professional development chair for Catalysts for Science Policy, is a former eLife Ambassador, and sits on the board for the early career research nonprofit group, Future of Research.

Celeste M. Sheftel is a 5th year Ph.D. candidate in the Molecular and Cellular Pharmacology Training Program at the University of Wisconsin-Madison in Dr. Laura Hernandez's lab. She serves on the professional development committee for Catalysts for Science Policy and is the national liaison for the Madison Chapter of the Graduate Women in Science.

Alejandra Canales is a 7th year Ph.D. candidate in the Neuroscience Training Program at the University of Wisconsin-Madison in Dr. Meyer Jackson's lab. She is passionate about advocating for graduate students and serves on the policy engagement committee for Catalysts in Science Policy as well as the Diversity Enhancement Committee for the Neuroscience Training Program.

\section{Acknowledgements}

The authors of this memo are members of Catalysts for Science Policy at the University of Wisconsin - Madison, which belongs to the Central Hub of the National Science Policy Network (NSPN). The authors would like to thank Dr. Stephanie Davis and Nabanita Nawar for their input and copyediting of this document. 